\title{
Just give them childcare: The COVID-19 pandemic as a natural experiment in parenting practices
}

\author{
Joshua K. Hartshorne ${ }^{1}$ \\ ${ }^{1}$ Department of Psychology and Neuroscience, Boston College \\ Abstract
}

\begin{abstract}
Correlations between parenting practices and child development outcomes are as established as anything in human behavior. Their causes remain controversial. Parenting practices are confounded with culture, socio-economic status, and genetics. As a general rule, randomized controlled experiments are impractical if not impossible. We use the COVID-19 pandemic school reopenings as a natural experiment to address this gap. A number of studies showed that the advent of the pandemic negatively affected families. Prior work tied increased child recreational screen time and decreased parent mental health specifically to school and daycare closures (rather than work-at-home policies, unemployment, fluctuating COVID rates, etc.). However, losses are different from gains, and just because losing childcare hurts families does not mean increasing childcare will help them. We use the fact that schools reopened at different times and to different degrees across the country, showing that return to in-person schooling decreased child recreational screen time and improved parent mental health. Again, we rule out potential confounds like work-from-home policies, COVID rates, and unemployment. The results indicate that addressing childcare gaps may be critical to improving child and family well-being.
\end{abstract}

Keywords: COVID-19, screen time, school reopening, child development

Richard Weissbourd, a senior lecturer at the Harvard Graduate School of Education, helped establish a campaign in Boston that urged parents to talk to their kids, and he organized focus groups with low-income parents. "You had some people working three jobs or dealing with the steady drizzle of helplessness and hopelessness," he recalled. "That makes it hard to have vibrant conversations with a baby. They'd say, 'Look, when I get home I have to clean and cook and do the laundry.' They're exhausted. They'd say, 'Sometimes we have to put our kids in front of the TV." "Weissbourd said ... "Maybe we have the model wrong. Maybe what we need to do is come in and bring dinner and help with the laundry and free up a parent to engage in more play with their child." 
Margaret Talbot, "The talking cure," The New Yorker

\section{Introduction}

A number of parenting practices are associated with better educational, health, and life outcomes, such as talking and reading to children, ensuring they get sufficient exercise, and minimizing screen time (Adelantado-Renau et al., 2019; Faught et al., 2017; Madigan, McArthur, Anhorn, Eirich, \& Christakis, 2020; Mundy et al., 2020; Orben \& Przybylski, 2019; Oswald \& Moore, 2020; Przybylski \& Weinstein, 2017; Stiglic \& Viner, 2019; Trinh, Wong, \& Faulkner, 2015). This has inspired public policy initiatives centered on educating parents and training them to utilize those practices (Obama, 2012; Organization et al., 2019; Rugg, 2019; Talbot, 2015). The implicit theory is that these are cultural problems with cultural solutions: parents do not know parenting best practices or do not know how to implement them or are insufficiently motivated to do so. If you can change parental preferences, you change parental behavior and ultimately child outcomes (Fig. 1, top).

The Cultural Theory assumes a causal relationship between parenting practices and outcomes. Two alternatives deny (or at least de-emphasize) any such relationship. Instead, "poor" parental practices and poor developmental outcomes are common effects of an underlying cause. The first notes that parents and children not only share an environment,

Funding for this work was provided by NSF 2030106. The author thanks Kathleen Oppenheimer for contributions to the analyses, Wesley Ricketts for valuable edits and feedback, and Emily Oster and Steve Pinker with help with data collection.

The project described in this paper relies on data from survey(s) administered by the Understanding America Study, which is maintained by the Center for Economic and Social Research (CESR) at the University of Southern California. The content of this paper is solely the responsibility of the authors and does not necessarily represent the official views of USC or UAS. The collection of the UAS COVID-19 tracking data is supported in part by the Bill \& Melinda Gates Foundation and by grant U01AG054580 from the National Institute on Aging, and many others.

Additional data used in the preparation of this article were obtained from the Adolescent Brain Cognitive Development (ABCD) Study (https://abcdstudy.org), held in the NIMH Data Archive (NDA). This is a multisite, longitudinal study designed to recruit more than 10,000 children age 9-10 and follow them over 10 years into early adulthood. The ABCD Study ${ }^{\circledR}$ is supported by the National Institutes of Health and additional federal partners under award numbers U01DA041048, U01DA050989, U01DA051016, U01DA041022, U01DA051018, U01DA051037, U01DA050987, U01DA041174, U01DA041106, U01DA041117, U01DA041028, U01DA041134, U01DA050988, U01DA051039, U01DA041156, U01DA041025, U01DA041120, U01DA051038, U01DA041148, U01DA041093, U01DA041089, U24DA041123, U24DA041147. A full list of supporters is available at https://abcdstudy.org/federal-partners.html. A listing of participating sites and a complete listing of the study investigators can be found at https://abcdstudy.org/consortium_members/. ABCD consortium investigators designed and implemented the study and/or provided data but did not necessarily participate in the analysis or writing of this report. This manuscript reflects the views of the authors and may not reflect the opinions or views of the NIH or ABCD consortium investigators. Additional support for this work was made possible from supplements to U24DA041123 and U24DA041147, the National Science Foundation (NSF 2028680), and Children and Screens: Institute of Digital Media and Child Development Inc. The ABCD data used in this report came from http://dx.doi.org/12805210.15154/1520584.

Yet additional data came from the US Census Bureau Household Pulse Survey, which can be found at https://www.census.gov/programs-surveys/household-pulse-survey/. Author contributions:

Correspondence concerning this article should be addressed to Joshua K. Hartshorne, McGuinn Hall 522, 140 Commonwealth Ave., Chestnut Hill, MA 02467. E-mail: joshua.hartshorne@bc.edu 
The Cultural Theory

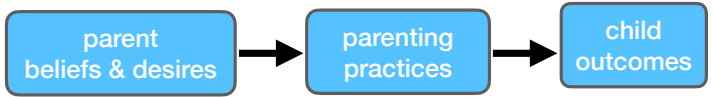

The Genetic Theory

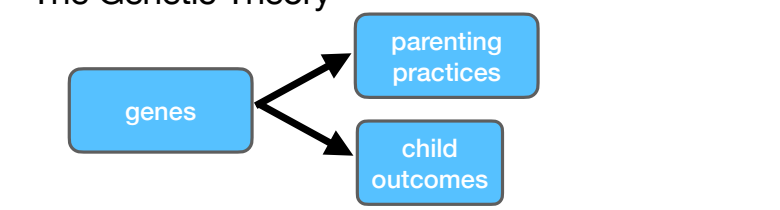

The Resource Theory

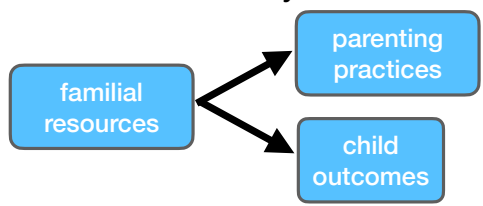
much beyond burdening the parents.

Figure 1. Alternative explanations of the relationship between parenting practices and outcomes.

they share genes (Harris, 2011; Pinker, 2003). On this Genetic Theory, parenting practices and child outcomes are co-determined by this shared genetic heritage. Outside of extremes

The third theory is exemplified by the Margaret Talbot quote above: much of the parent-to-parent variation is driven not by parental beliefs and desires but by parent resources. For some parents, simply feeding, clothing, and housing their children fully consumes their resources, with little left for conversation, much less enrichment activities. Lack of resources is also associated with poor parent mental health, which itself can degrade parenting behavior Glass, Simon, \& Andersson, 2016; Mikolajczak \& Roskam, 2018; Parkes, Sweeting, \& Wight, 2015). Authorities can harangue over-burdened parents about managing screen time all they like, but parents will still prioritize clothing and feeding their children. Nor would we want them to do otherwise: society is not served by naked, starving children who are nonetheless blissfully screen-free. In fact, educating over-burdened parents about un-met and perhaps un-meetable parenting obligations may backfire: feeling that one lacks the resources to meet one's parenting obligations may itself contribute to poor parental mental health, emotional distance from the child, and other negative outcomes (Mikolajczak \& Roskam, 2018). In essence, insufficient conversation, exercise, and non-screen recreation are structural problems that demand structural solutions. They may not even be problematic in and of themselves but are rather symptoms of familial distress (Hartshorne et al., 2021). As with the Genetic Theory, intervening on parenting practices may not do

\section{outcomes.}

This debate is part of a larger scientific debate about the causes of individual behavioral
differences: how much of stable behavioral differences between individuals are due to
differences in the individuals and how much are due to differences in their circumstances
(Ericsson, 2014; Harris, 2011; Pinker, 2003; Robinson, 2004)? This debate is difficult to
resolve because individuals and their circumstances are typically confounded in the world. 
Experimental manipulation is the gold standard, but sizeable experimental manipulations of the individual are extremely difficult. For instance, many of the programs training parents to talk more to their children show little long-term - or even short-term - effect on parental behavior (Gilkerson, Richards, \& Topping, 2017; Smith, 2015; Suskind et al., 2016; Talbot, 2015). Sizeable manipulations of circumstance are not much easier and usually involve large-scale government programs (e.g., Puma et al., 2010). Manipulations of genetics are not (yet?) widely feasible.

Conveniently (for some value of "convenient"), the COVID-19 pandemic has provided a massive natural experiment, drastically diminishing parental resources. In particular, daycares, schools, after-school programs, and camps closed, and other external supports such as babysitters and grandparents became unavailable. Consistent with the Structural Theory, screen time increased, exercise decreased, parents read less to their children, and parent mental health declined (Androutsos, Perperidi, Georgiou, \& Chouliaras, 2021; Barnett \& Jung, 2021; Bronikowska, Krzysztoszek, Łopatka, Ludwiczak, \& Pluta, 2021; Carroll et al., 2020; Hartshorne et al., 2021; Medrano et al., 2021; Ng, Cooper, McHale, Clifford, \& Woods, 2020; Olive et al., 2020; Paterson et al., 2021; Sciberras et al., 2020; Stienwandt et al., 2020; Takaku \& Yokoyama, 2020).

Critically, Hartshorne et al. (2021) showed that the increase in screen time and the decrease in parent mental health were both directly associated with loss of childcare rather than other pandemic-related phenomena such as decreased mobility, stay-at-home orders, or local disease rates. ${ }^{1}$ Changes in screen time and parent mental health were time-locked to the closure of daycares and schools but not other pandemic-related phenomena, and effects were dose dependent: the more parents faced childcare challenges, the more screen time increased and parent mental health decreased. The two may be related: parents struggling with mental health may have less energy for their children and turn to screens for support when other supports are not available (Hartshorne et al., 2021; Johnson \& Padilla, 2019).

\section{Losses vs. gains}

While these findings certainly do not rule out any role for culture or genetics, they indicate a large role for parent resources - specifically, external childcare support (including school). However, the finding is unidirectional: losing resources caused an increase in screen time and decrease in parental mental health. This does not necessarily mean that gains in resources would decrease screen time and improve mental health. For one thing, humans respond differently to losses relative to gains (Kahneman \& Tversky, 2013). Moreover, the lockdowns of 2020 may have created new habits for families with regards to screen time, habits that may be difficult to break (Richtel, 2021). Relatedly, mental health is not fully elastic: removing the stressor does not necessarily resolve the stress, and continued poor mental health may make it difficult for families to resume healthy habits. Indeed, one small preliminary study reported that recreational screen time actually continued to increase after schools reopened in the Netherlands relative to when they were closed (Ten Velde et al., 2021).

In addition to the theoretical implications, there are enormous practical implications to

\footnotetext{
${ }^{1}$ No studies disentangle the causes of decreased exercise or parental reading, and we do not do so here.
} 
understanding how increases in childcare support affects families. Public discourse has been riven by debates about whether and when to reopen schools - a question which itself turns partly on estimating the cost of not reopening (Bond, Dibner, \& Schweingruber, 2020; Gilbert et al., 2020; Kurtz, 2021). Although this seems to be mostly resolved (at least in countries with adequate access to vaccines), this will not be the last time the question arises as to how much school reopening should be prioritized (e.g., after natural disasters). Moreover, there is a broader debate in the United States about whether to increase publicly-funded childcare for the expressed purpose of de-burdening parents. A better understanding of what the benefits are will help inform discussions of whether the cost is worth it.

For this question, too, the pandemic has provided a natural experiment as schools return to in-person learning. A helpful feature (scientifically) is that there has been a great deal of variability in the timing and nature of back-to-school plans. For example, on September 25, 2020, Puerto Rico and the District of Columbia were fully virtual; 2 states only allowed remote or hybrid instruction; 4 states required schools to offer part- or full- time in-person instruction; 5 states had state-ordered regional school closures; and 39 states left school reopening decisions were left to individual school districts or local health authorities ("Map," 2021). Data from the COVID-19 School Response Dashboard on a non-random sample of 12 million students (about $23 \%$ of the 53 million K-12 students in the US) show that during each two-week period of the 2020-2021 school year through February 2021, between $38 \%$ and $67 \%$ of students enrolled in schools that shared such data were attending school in person ("COVID-19 school response dashboard," 2021). Thus, families in neighboring communities - or even in the same community - vary in how much childcare was restored and when. This allows us to investigate effects of schooling policy without temporal confounds.

A secondary but related question is the effect of "hybrid" schooling, where children participate in a combination of in-person and virtual instruction. One possibility is that the addition of some in-person schooling relative to fully virtual schooling should improve parental mental health and decrease screen time, but not to the same extent as return to fully in-person schooling. Alternatively, hybrid schooling may not actually provide much benefit. It may not provide enough childcare to allow the parent to meet both their work and home responsibilities. Indeed, the additional costs of in-person schooling (transportation, coordinating schedules, packing lunches, complying with safety regulations, etc.) combined with the routine-disrupting odd schedules of many hybrid schooling programs may outweigh any benefits.

\section{Methods}

\section{Study and Data Selection}

Based on our a priori defined research questions, we conducted an exhaustive search for data sets reporting both schooling status and at least one of the following: child screen time, parent mental health, and family stress. In addition to our own KidTalk Family Environment Survey (see below), which was designed for this purpose, we were able to identify three external data sets (Understanding America, Adolescent Brain \& Cognitive Development study, Census Household Pulse), described below. Some otherwise promising data sets were 
Table 1

Critical measures available in each of the five datasets.

\begin{tabular}{llllll}
\hline & Kid Talk 2 & Kid Talk 3 & ABCD & Understanding America & Census \\
\hline $\mathrm{N}$ & 162 & 459 & 5,953 & 2,694 & 270,265 \\
Outcomes & & & & & \\
$\quad$ Parent Burden & $\mathrm{Y}$ & $\mathrm{Y}$ & $\mathrm{Y}$ & $\mathrm{N}$ & $\mathrm{N}$ \\
$\quad$ Screen Time & $\mathrm{Y}$ & $\mathrm{Y}$ & $\mathrm{Y}$ & $\mathrm{N}$ & $\mathrm{N}$ \\
$\quad$ Parent Mental Health & $\mathrm{Y}$ & $\mathrm{Y}$ & $\mathrm{N}$ & $\mathrm{Y}$ & $\mathrm{Y}$ \\
Alternatives & & & & & $\mathrm{N}$ \\
COVID Prevalence & $\mathrm{N}$ & $\mathrm{N}$ & $\mathrm{Y}$ & $\mathrm{Y}$ & $\mathrm{Y}$ \\
Employment Loss & $\mathrm{Y}$ & $\mathrm{Y}$ & $\mathrm{Y}$ & $\mathrm{Y}$ & $\mathrm{Y}$ \\
Working from Home & $\mathrm{N}$ & $\mathrm{N}$ & $\mathrm{N}$ & $\mathrm{Y}$ & \\
\hline
\end{tabular}

excluded without analysis either because we could not obtain them (RAPID-EC) or because they did not provide enough information about schooling status, such as not distinguishing between in-person, online, and hybrid schooling models (Axios-Ipsos, AP-NORC/SAP).

Throughout, our analyses focus on children in formal schooling, excluding children who are homeschooled, not schooled, or on summer vacation. While we did conduct some exploratory analyses of these sub-populations, the sample sizes were small, the results were inconsistent, and we had no clear predictions. These analyses are not reported.

All four datasets are rich and contain many measures that we did not explore and are not discussed below. For completeness, several exporatory analyses are described in the Supplementary Online Materials.

KidTalk Pandemic Parenting Survey. The KidTalk survey was conducted by our research group in conjunction with the KidTalk Project (https://kidtalkscrapbook.org). The survey was programmed using Qualtrics. Survey responses from the first wave (Spring 2020) are reported in Hartshorne et al. (2021). The survey was available in English and Spanish, but all participants who completed the survey in the 2nd and 3rd waves completed it in English. The survey was publicized via social media, the KidTalk Project email list, professional and parenting email lists, popular parenting newsletters, and similar forums.

2nd Wave. The second wave ran from Sep. 14, 2020 to Jan 21, 2021. A full list of questions can be found at https://osf.io/vz25n/. Respondents reported the number and ages of children living in their home and the schooling status of their youngest school-aged child. They reported change in time spent on childcare separately for themselves and the other adults in the household (less, same, $+1 \mathrm{hr},+2 \mathrm{hrs},+3 \mathrm{hrs},+4 \mathrm{hrs},+5$ or more hrs). They reported their own level of worrying on a 5-point Likert scale for each of a) having enough food or money, b) themselves or a family member getting sick, and c) everything else. They reported whether household income had decreased due during the pandemic. Finally, they reported change in recreational screen time for their youngest child (less, same, $+.5 \mathrm{hrs},+1$ $\mathrm{hr},+2 \mathrm{hrs},+(>2) \mathrm{hrs})$. Nonetheless, we expect that parental availability is determined in part by the schooling policy for older siblings. Changes in childcare hours or screen time were in comparison to a typical day before the pandemic. Throughout, we recoded 'less' as 
'-1,' 'same' as '0,' and "x or more" as its lower bound (e.g., ' 5 or more hours' was coded as '5'). Additional questions about enrichment activities and parental sleep were included for purposes of a separate study and not analyzed here.

Analysis of the 2nd wave survey focuses on the 162 parents who reported a school-aged child living at home. We excluded respondents who reported that this child was not in school $(\mathrm{N}=4)$ or homeschooled $(\mathrm{N}=12)$. Otherwise, 106 were attending school fully online, 37 fully in-person, and 19 with hybrid instruction. A majority of included parents reported one $(\mathrm{N}=38)$ or two $(\mathrm{N}=86)$ children total, with a maximum of 7 . Race and ethnicity of the participants appear in Table SI1

3rd Wave. Wave 3 was updated to reflect our better understanding of the situation on the ground, our shifted focus to school-aged children and schooling policy, and the passage of nearly a year of pandemic (which confounded direct comparison to pre-pandemic life with child age, since children were nearly a year older relative to pre-pandemic). A full list of questions can be found at https://osf.io/vz25n/. Thus, parents again reported their own race and ethnicity, whether they had school-aged children, number and ages of children, and schooling policy for their youngest school-aged child (fully in-person, fully online, hybrid, homeschooled, not schooled). They compared their typical weekday in the prior week against a hypothetical non-pandemic world in terms of a) hours spent on childcare (8+ hours fewer to $8+$ hours more); b) time spent on childcare by other adults in the household (less, same, more); c) how much of any additional childcare took place during work hours $(0 \%-100 \%)$; d) their own level of stress (11-point Likert scale); and e) hours of recreational screen time by the youngest school-aged child ( 5 hours fewer to 5 hours more). Where the youngest school-aged child was in hybrid education, we asked how many hours of in-person school they had in the previous week ( 0 to $11+$ ). Because $84.2 \%$ of families reported the maximum on that scale $(11+)$, children in hybrid instruction were treated as a single category rather than along a continuum of hours of in-person instruction. Respondents also reported absolute number of hours of recreational screen time for the youngest school-aged child on the typical weekday in the prior week (0 to 10). They reported whether anyone in the household had lost employment or had hours reduced due to the pandemic. Finally, they reported both their own level of worry and happiness today on 5-point Likert scales. They also reported hours of sleep the previous evening, which was not analyzed. As in Wave 2, where response scales ended in "X or more," this was numerically recoded as ' $\mathrm{X}$ ' (so "5 or more hours" would be recoded as 5).

Most participants had two $(\mathrm{N}=250)$ children or one $(\mathrm{N}=118)$ child; the remaining participants had between 3 and 6 children. Race and ethnicity of the participants appear in Table SI2. We excluded respondents who reported that their youngest school-aged child was not in school $(\mathrm{N}=14)$ or being homeschooled $(\mathrm{N}=35)$. Otherwise, 240 were attending school fully online, 124 fully in-person, and 95 with hybrid instruction.

\section{Adolescent Brain Cognitive Development}

The Adolescent Brain Cognitive Development (ABCD) study is a multi-site longitudinal study of adolescent brain development and health. A set of supplemental COVID-19 questions were administered three times to participants (ages 10 to 15 years, $\mathrm{M}=13$ ) and their parents 
in May/June, July, and August 2020. 7995 adolescents reported their current schooling status during at least one wave; we focus on the 5953 who were participating in online $(\mathrm{N}=$ $6208)$, in-person $(\mathrm{N}=151)$, or hybrid $(\mathrm{N}=163)$ education at some point; the remainder reported being on summer vacation, being homeschooled, not being schooled, or 'other' status. Parents also reported school closures but the questions did not clearly distinguish between online, hybrid, and in-person options, so these responses were not used for analysis.

Three different measures of non-academic screen time were reported. Both parents and adolescents separately estimated total daily screen time. The adolescents also estimated total time for each of several activities (texting, streaming, gaming, etc.), which we added together to make the third measure (because this sometime totalled more than $24 \mathrm{hrs} /$ day, we enforced a ceiling of $24 \mathrm{hrs}$ ). Parents reported the degree to which childcare responsibilities interfered with their work or household duties (two questions, which we averaged together). Two other demographic variables we used were the number of extended family members and close friends diagnosed with COVID $(\max =10)$ and whether household income had decreased since January 2020 due to the pandemic. ${ }^{2}$

\section{Understanding America Study}

The Understanding America Study has administered the Understanding Coronavirus in America tracking survey approximately every two weeks to a representative panel of about 8,000 people in the United States (Kapteyn et al., 2020). UAS began asking about schooling status (fully virtual, fully online, hybrid, homeschool, other) in Wave 14 (9/16/2020 - 10/12/2020), with the exceptions of the Waves 16 and 17 . We analyzed through Wave $27(4 / 14 / 2021-5 / 25 / 2021)$, for a total of 12 waves. Altogether, 2694 individuals reported schooling status for a child at least once, with an average of 8.1 times. Note that whereas in most waves parents were asked about one randomly-selected child, in Wave 14, parents were asked about all children. We excluded responses that indicated homeschooling $(\mathrm{N}=1,180)$ or "other" schooling status $(\mathrm{N}=1,584)$, resulting in 5,618 "fully in-person" observations, 10,243 "fully virtual" observations, and 3,172 "hybrid" observations.

Participants also responded to the four questions on the Patient Health Questionnaire - 4 [PHQ-4; Kroenke, Spitzer, Williams, and Löwe (2009); but see Ransing et al. (2020)], a brief four-item screening tool that identifies symptoms of anxiety and/or depression. They also reported number of days worked in the past week and the number of those worked from home. We combined these into a continuous metric of proportion of time working from home $(0-1)$. Finally, participants reported employment status, which we dichotomized as "unemployed" ("sick/other leave," "unemployed-laid off," "unemployed-looking") or not ("currently working," "retired, so not in labor force," "not in labor force \& not retired"). Other questions were not relevant to present purposes and were not analyzed.

\section{Census Household Pulse Survey}

The Census Household Pulse Survey (Fields et al., 2020) is a 20-minute online national survey of households that has been conducted every two weeks since May, 2020. We analyzed data from Wave 14 (9/2/2020 - 9/14/2020) through Wave 30 (5/12/2021 - 5/24/2021),

\footnotetext{
${ }^{2}$ There was also a count of immediate family members, but this was usually the same.
} 
during which participation ranged from 58,729 households to 110,019, depending on wave. A total of 270,265 households reported at least one child enrolled in school. Respondents reported how many days out of the last week that the student(s) in the household had live interaction with a teacher, whether virtual or in-person on the following scale: $0,1,2-3$, $4+{ }^{3}$ We recoded "2-3" as 2.5 and " $4+$ " as $4.5 .^{4}$ Participants reported whether they had lost employment and were currently unemployed as a result of the pandemic. Participants also reported their own mental health using version of the Patient Health Questionnaire - 4 (PHQ-4), modified to query the previous 7 days rather than the previous 14, as is typical and as was used in Understanding America. We did not analyze data from any other questions in the survey.

\section{Data analysis}

We used R [Version 4.0.3; R Core Team (2020)] and the R-packages dplyr [Version 1.0.6; Wickham, François, Henry, and Müller (2021)], ggplot2 [Version 3.3.3; Wickham (2016)], lubridate [Version 1.7.10; Grolemund and Wickham (2011)], stringr [Version 1.4.0; Wickham (2019)], and tidyverse [Version 1.3.0; Wickham et al. (2019)] for our analyses and R [Version 4.0.3; R Core Team (2020)] and the R-packages knitr [Version 1.31; Xie (2015)], and papaja [Version 0.1.0.9997; Aust and Barth (2020)] to create a reproducible manuscript. In the ABCD, Understanding America, and Census Household Pulse datasets, some individuals responded to the questionnaire at multiple timepoints. However, there were too few observations per subject - particularly across schooling policies - to sensibly estimate random effects of subjects. Instead, we averaged across observations per subject per schooling type. We then treated these means as independent even though some of them represented the same subject under different schooling policies. This may result in somewhat conservative p-values.

\section{Results}

We considered how school reopening policy affected parental childcare burden, child screen time, and parental mental health.

\section{Preliminary: Schooling Policy and Parental Burden}

We were able to use the KidTalk survey data and the ABCD data to estimate the effect of schooling policy and childcare burden (see Table ??. As shown in Figure 2, KidTalk respondents reported that childcare burden varied significantly by school reopening status

\footnotetext{
${ }^{3}$ Here, we follow the text in the published survey. The data dictionary states that respondents were only asked about virtual interactions, but discussions with an official at the Census confirmed that this is incorrect.

${ }^{4}$ In the final three waves (28-30), participants were additionally asked about whether the child received any in-person instruction, virtual instruction, or "on your own" schoolwork (participants could report 'yes' to all three), as well as whether the child was in hybrid education. However, these appear to be somewhat noisy measures. Of respondents who reported that their children received both in-person and virtual instruction in the last week, a full $13 \%$ reported that their children were not in hybrid education. Similarly, of those reporting their child was in hybrid education, $25 \%$ reported that their children received no in-person instruction in the prior week. This may reflect confusion when different children in the same household had different schooling regimes. Given this uncertainty, and given that these questions were only asked for a relatively small subset of subjects, we did not use them in analysis.
} 
Table 2

Overview of results. Where no results are available, the cell is left blank. The top section reports whether key outcome variables varied significantly by schooling policy ( $Y=$ 'Yes,' $N=$ 'No,' $M=$ 'Mixed'). The bottom section reports whether significant results in the top section could be explained away by any of the three 'alternative' predictors.

\begin{tabular}{|c|c|c|c|c|c|}
\hline & Kid Talk 2 & Kid Talk 3 & $\mathrm{ABCD}$ & Understanding America & Census \\
\hline \multicolumn{6}{|c|}{ Affected by Schooling Policy? } \\
\hline Parent Burden & $\mathrm{Y}$ & $\mathrm{Y}$ & $\mathrm{N}$ & & \\
\hline Screen Time & $\mathrm{Y}$ & $\mathrm{Y}$ & $\mathrm{Y}$ & & \\
\hline Parent Mental Health & $\mathrm{N}$ & $\mathrm{N}$ & & $\mathrm{Y}$ & $\mathrm{Y}$ \\
\hline \multicolumn{6}{|l|}{ Explained away by? } \\
\hline COVID Prevalence & & & $\mathrm{N}$ & $\mathrm{N}$ & \\
\hline Employment Loss & $\mathrm{N}$ & $\mathrm{N}$ & $\mathrm{N}$ & $\mathrm{N}$ & $\mathrm{N}$ \\
\hline Working from Home & & & & $\mathrm{N}$ & $\mathrm{N}$ \\
\hline
\end{tabular}

(Wave 2: $F(2,159)=26.28, M S E=3.48, p<.001, \hat{\eta}_{G}^{2}=.248$; Wave $3: F(2,310)=5.39$, $\left.M S E=4.72, p=.005, \hat{\eta}_{G}^{2}=.034\right)$. In both waves, childcare burden was significantly less for parents whose children were receiving in-person instruction relative to either hybrid or virtual instruction, as assessed by holm-bonferonni-corrected pairwise t-tests (corrected p's $<=0.011$ ). In neither Wave was there a significant difference between hybrid and virtual education, suggesting that hybrid education did little to decrease parental burden (corrected p's $>=0.11$ ). Similarly, parents in the ABCD dataset reported greater interference on their work and household duties when their children were in hybrid or fully online schooling, though the differences did not reach significance $(F(2,5,493)=0.85, M S E=0.29, p=.427$, $\left.\hat{\eta}_{G}^{2}=.000\right)$.

A

KidTalk Wave 2

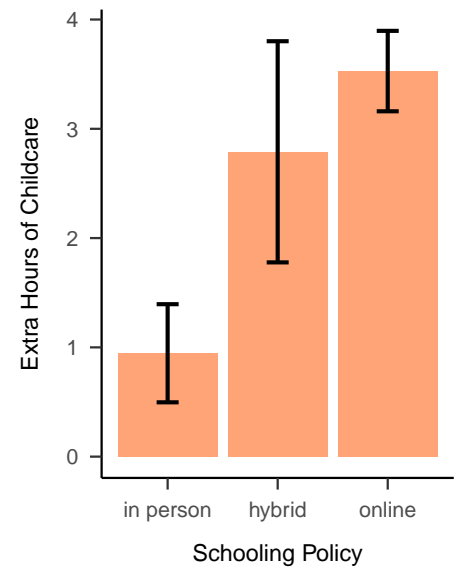

B KidTalk Wave 3

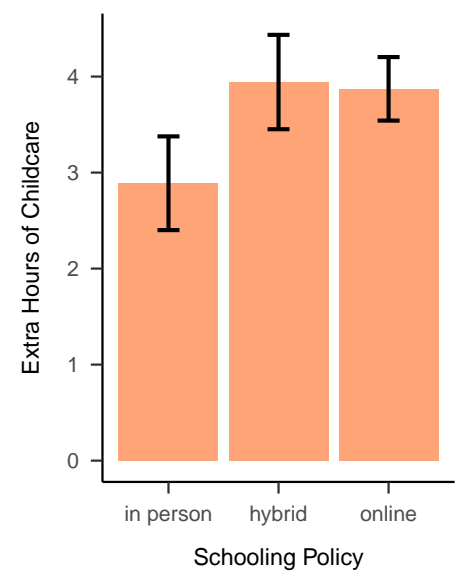

Figure 2. Additional hours of childcare provided by parents per day compared to if there were no pandemic, in KidTalk Wave 2 (left) and Wave 3 (right). Error bars indicate 95\% CI. 


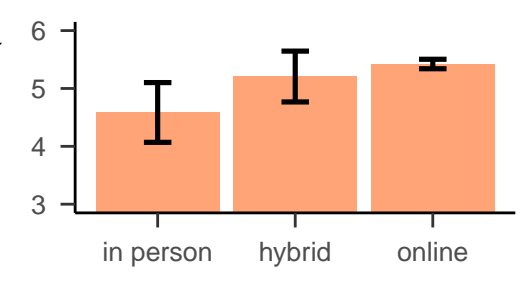

Schooling Policy

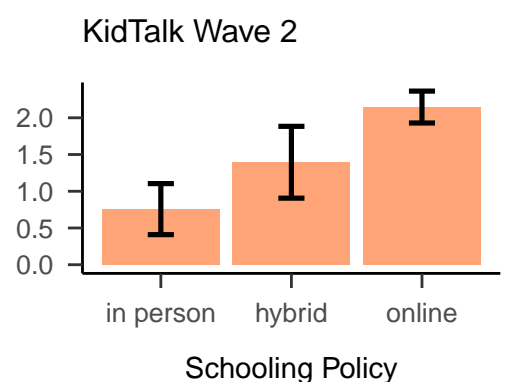

We were able to assess the effect of schooling policy on screen time using the KidTalk

Both KidTalk waves showed clear evidence of an effect of schooling policy on screen time (Wave 2: $F(2,159)=22.12, M S E=1.26, p<.001, \hat{\eta}_{G}^{2}=.218 ;$ Wave 3: $F(2,456)=6.05$, $M S E=2.87, p=.003, \hat{\eta}_{G}^{2}=.026$ ) (Figure 3). Holm-bonferonni-corrected t-tests showed that in both waves, screen time was less when children were in fully in person relative to fully virtual (Wave 2: 1.39 fewer hours, $\mathrm{p}=0.000000003$; Wave 3: 0.62 fewer hours, $\mathrm{p}=$ 0.00035). Screen time was numerically less when children were fully in person compared to hybrid instruction, but the difference did not survive correction for multiple comparisons (Wave 2: 0.64 fewer hours, $\mathrm{p}=0.14$; Wave 3: 0.22 fewer hours, $\mathrm{p}=0.17$ ). The differences between hybrid and fully online learners were significant in Wave 2 but not Wave 3 (Wave 2: 0.75 fewer hours, $\mathrm{p}=0.024$; Wave 3 : 0.41 fewer hours, $\mathrm{p}=0.5$ ).

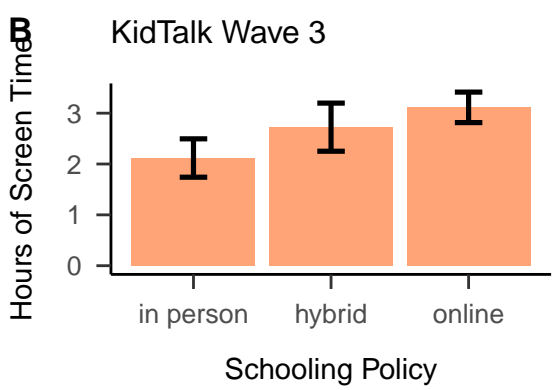

Figure 3. Change in daily non-academic screen time, by schooling policy. Top Left: KidTalk Parenting Survey, Wave 2 (Sep - Jan). Top Right: KidTalk Parenting Survey, Wave 3 (Jan Mar). Bottom: ABCD Dataset. Error bars represent 95\% CI.

We obtained similar results with the $\mathrm{ABCD}$ data (Figure 3). We report results averaging across the three estimates of screen time (see Method); results were qualitatively similar for each of three analyzed individually. There was a small but significant effect of schooling status $\left(F(2,6,519)=5.10, M S E=10.73, p=.006, \hat{\eta}_{G}^{2}=.002\right)$. Tukey contrasts revealed that adolescents in fully in-person instruction had on average 50 fewer minutes of recreational screen time than those in fully online schooling $(\mathrm{t}(6519)=-3.1, \mathrm{p}=0.0055$. In contrast, neither the difference between fully in person and hybrid nor the difference between hybrid and fully online were signficiant ( $p \mathrm{~s}>=0.21)$. 


\section{Schooling Policy and Caregiver Mental Health}

We were able to assess the impact of schooling policy on caregiver mental health using the Understanding America, Census Household Pulse, and KidTalk data (see Table ??.

Results for Understanding America data are shown in Figure 4. One-way ANOVA revealed a significant effect of schooling policy on mental health $(F(2,3,817)=8.24$, $\left.M S E=7.78, p<.001, \hat{\eta}_{G}^{2}=.004\right)$. Pairwise Tukey contrasts revealed that parents of fully in-person students reported better mental health than parents of full virtual students $(\Delta M=-0.42,95 \%$ CI $[-0.66,-0.17], t(3,817)=-3.98, p<.001, \mathrm{~d}=0.15)$ or hybrid students $(\Delta M=-0.33,95 \%$ CI $[-0.61,-0.04], t(3,817)=-2.69, p=.020, \mathrm{~d}=0.12)$. The difference between fully virtual and hybrid was not significant $(\Delta M=0.09,95 \%$ CI $[-0.18$, $0.36], t(3,817)=0.79, p=.709, \mathrm{~d}=0.032)$.
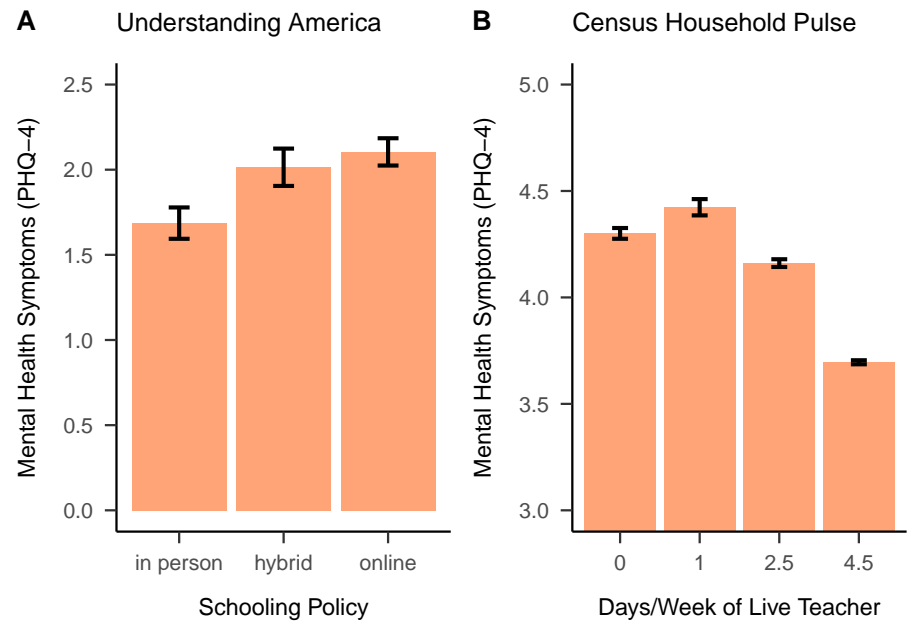

Figure 4. Mental health, as measured by the PHQ-4, by schooling policy (Understanding America, left) or days of live instruction (Census Household Pulse, right), with 95\% confidence intervals. A score of 0-2 on the PHQ-4 is considered normal, 3-5 is mild depression or anxiety symptoms, 6-8 is moderate, and 9-12 is severe.

For parents in the Census Household Pulse, days/week of live schooling (virtual or in-person) correlated negatively with poor mental health symptoms $(b=-0.16,95 \% \mathrm{CI}$ $[-0.17,-0.15], t(225300)=-32.99, p<.001$, standardized coefficient $=-0.584877)$.

KidTalk data numerically suggested lower levels of worry and stress and higher levels of happiness were associated with fully in-person schooling, but none of the analyses reached significance (see Supplementary Online Materials).

Thus, all three datasets indicated better caregiver mental health the more schooling their child was receiving - results that were significant for the two larger datasets but not for the lower-powered KidTalk datasets. Interestingly, there was again some indication that hybrid provided little advantage over fully virtual. 


\section{Alternative Explanations}

The pandemic affected families in a number of ways beyond changing schooling policy. We considered three classes of changes that could have affected screen time.

Disease Prevalence. Families were affected by the pandemic in that they were living through a pandemic. Both ABCD and Understanding America solicited information on the number of close contacts who had been diagnosed with COVID and subjective self-assessment of likelihood that the respondent themself would get COVID (measures are slightly different; see 'Method'). Each of these measures can be used to estimate local severity of the pandemic.

For ABCD, neither measure varied significantly by schooling policy (respectively: $F(2,1,594)=0.88, M S E=2.25, p=.417, \hat{\eta}_{G}^{2}=.001 ; F(2,5,867)=1.25, M S E=1.01$, $\left.p=.288, \hat{\eta}_{G}^{2}=.000\right)$. For Understanding America, both measures did (respectively: $F(2,18,630)=22.27, M S E=99.41, p<.001, \hat{\eta}_{G}^{2}=.002 ; F(2,19,017)=12.41, M S E=$ $\left.515.93, p<.001, \hat{\eta}_{G}^{2}=.001\right)$, but in opposite directions: people whose children were in fully in-person schooling knew more people who had been diagnosed with COVID relative to fully virtual $(\Delta M=1.09,95 \%$ CI $[0.70,1.48], t(18,630)=6.52, p<.001)$ but assessed themselves to be at (very slightly) less risk than those whose children were in fully virtual schooling $(\Delta M=-1.79,95 \%$ CI $[-2.68,-0.91], t(19,017)=-4.76, p<.001)$. COVID rates did not explain away the relationship between schooling policy and screen time in the ABCD dataset or between schooling policy and mental health in the Understanding America dataset (see Supplementary Online Materials). (Recall that ABCD does not have parental mental health data and Understanding America does not have screen time data).

Loss of Employment. Many families experienced unemployment or decreased hours, which disrupted routines and likely increased stress. KidTalk, ABCD, Understanding America, and Census Household Pulse all included information about loss of employment or decreased hours.

There was no association between schooling policy and loss of employment in either KidTalk Wave $3\left(F(2,456)=0.00, M S E=0.16, p=.996, \hat{\eta}_{G}^{2}=.000\right)$ or ABCD $\left(F(2,7,574)=0.60, M S E=0.25, p=.547, \hat{\eta}_{G}^{2}=.000\right)$. In KidTalk Wave 2, loss of employment varied slightly by schooling policy $(F(2,159)=3.89, M S E=0.19, p=.022$, $\left.\hat{\eta}_{G}^{2}=.047\right)$. However, post hoc Tukey contrasts showed that this was due to families with children in fully in-person schooling being more likely to have lost employment than those in fully online schooling $(\Delta M=0.20,95 \%$ CI $[0.00,0.40], t(159)=2.35, p=.052)$, which would not explain the increase in screen time for the latter. Understanding America participants likewise reported a significantly relationship between current unemployment and schooling policy $\left(F(2,18,953)=168.44, M S E=0.14, p<.001, \hat{\eta}_{G}^{2}=.017\right)$, but this reflected lower unemployment for parents whose children were fully in person relative to those whose children were fully virtual $(\Delta M=-0.11,95 \%$ CI $[-0.12,-0.09], t(18,953)=-17.42, p<.001)$ or hybrid $(\Delta M=-0.03,95 \%$ CI $[-0.05,-0.01], t(18,953)=-3.34, p=.002) .{ }^{5}$ Likewise, analysis of Census data showed that the probability of the respondent being unemployed was negatively associated with the number of hours of instruction their child received $(b=-0.09$,

\footnotetext{
${ }^{5}$ The highest unemployment rate was for fully virtual, which was significant higher than for hybrid $(\Delta M=0.08,95 \%$ CI $[0.06,0.10], t(18,953)=10.58, p<.001)$.
} 
$95 \%$ CI $[-0.10,-0.08], z=-17.84, p<.001)$.

Thus, there was no consistent relationship between unemployment and schooling policy, in contrast to the consistent relationship between schooling policy on the one hand and screen time and parent mental health. In any case, follow-up analyses confirmed that schooling status affected both screen time \& parental stress independent of pandemic-related employment issues (See Supplementary Online Materials).

Working from Home. Adults who were still working either had to work from home (disrupting routines) or work outside of the home (during a pandemic). Both Understanding America and the Census collected data about whether the respondent was working from home. For Understanding America, percentage of days worked from home varied significantly by schooling policy $\left(F(2,12,019)=79.18, M S E=0.20, p<.001, \hat{\eta}_{G}^{2}=.013\right)$, reflecting more working from home for parents whose children were fully virtual than for those whose children were fully in person $(\Delta M=0.11,95 \%$ CI $[0.09,0.13], t(12,019)=11.76, p<.001)$ or hybrid $(\Delta M=0.09,95 \%$ CI $[0.07,0.12], t(12,019)=8.12, p<.001)$. The Census, in contrast, showed that the more hours of live schooling the child had, the more likely the respondent was to work from home $(b=0.03,95 \%$ CI $[0.02,0.03], t(260406)=40.27$, $p<.001)$.

In neither case did working from home explain away the association between screen time and mental health. For Understanding America, we fit a linear model for PHQ4 scores with linear predictors of school policy and percentage of time worked from home, along with their interaction. The main effect of school policy remained $(F(2,3,544)=9.73, M S E=6.36$, $\left.p<.001, \hat{\eta}_{G}^{2}=.005\right)$. The effect of working from home was not significant $(F(1,3,544)=0.89$, $\left.M S E=6.36, p=.345, \hat{\eta}_{G}^{2}=.000\right)$, nor was the interaction $(F(2,3,544)=0.35, M S E=6.36$, $\left.p=.705, \hat{\eta}_{G}^{2}=.000\right)$. For the Census, we modeling PHQ4 scores with linear predictors of days of instruction and whether an adult in the household was working from home, along with their interaction. Working from home was associated with significantly better mental health $\left(F(1,259,163)=306.91, M S E=12.83, p<.001, \hat{\eta}_{G}^{2}=.001\right)$. Critically, the effect of instructional hours remained significant $(F(1,259,163)=715.53, M S E=12.83$, $\left.p<.001, \hat{\eta}_{G}^{2}=.003\right)$. While there was a slight but significant interaction such that days of instruction had a larger effect when no adults were working from home $(F(1,259,163)=16.23$, $\left.M S E=12.83, p<.001, \hat{\eta}_{G}^{2}=.000\right)$, the marginal trends indicated better mental health with more days of instruction, whether the respondent was working from home $(\mathrm{b}=-0.1333332$, $\mathrm{CI}=[-0.1461159,-0.1205505])$ or not $(\mathrm{b}=-0.1700179, \mathrm{CI}=[-0.1461159,-0.1575604])$.

Unfortunately, we did not have any datasets with measures of both screen time and working from home, and thus we could not test for an association.

\section{Discussion}

Analyses strongly confirmed the hypothesis that children engage in less recreational screen time and parents experience better mental health when children are physically in school. These findings could not be explained away by other pandemic-associated phenomena, such as community disease rates, loss of employment, or work-from-home policies.

In contrast, the likely mediator is childcare: parents spent more time on childcare when their children were not physically in school (see above). The KidTalk data allow us to test 
for a dose-dependent response. The pandemic-related increase in childcare predicted greater child recreational screen time in both waves: significantly in Wave $2(b=0.27,95 \%$ CI [0.19, $0.35], t(160)=6.47, p<.001)$ and trending towards significance in Wave $3(b=0.07,95 \%$ CI $[-0.01,0.15], t(311)=1.70, p=.091)$. There was also some evidence of dose-dependent association with mental health. In Wave 2 , the association with worry about food \& money did not reach significance $(b=0.02,95 \%$ CI $[-0.04,0.08], t(160)=0.70, p=.483)$, but increased childcare did predict greater worry about sickness $(b=0.09,95 \%$ CI $[0.02,0.17]$, $t(160)=2.55, p=.012)$ and 'all else' $(b=0.11,95 \%$ CI $[0.04,0.19], t(158)=2.88, p=.005)$. In Wave 3, greater increase in pandemic-related childcare predicted significantly greater stress $(b=0.11,95 \%$ CI $[0.02,0.19], t(309)=2.45, p=.015)$ and significantly greater worry $(b=0.07,95 \%$ CI $[0.02,0.11], t(306)=2.83, p=.005)$, though it did not predict happiness $(b=-0.02,95 \%$ CI $[-0.05,0.02], t(305)=-1.06, p=.289)$.

The effect of schooling policy on family well-being appears to be extremely robust. They were observed repeatedly across four large, national datasets. Moreover, they complement our prior findings - also from multiple large, national datasets - that losing childcare increased recreational screen time and worsened parent mental health (Hartshorne et al., 2021). Importantly, while the prior findings depended on (often within-family) pre- and post-comparisons, which involve an inherent temporal confound, the current results involve cross-family comparisons that are not temporally confounded. Thus, changes in childcare availability have similar results whether measured longitudinally or cross-sectionally and whether in terms of losses or gains, indicated that this is a powerful, robust effect.

Interestingly, with regards to screen time and parent mental health, hybrid education was not consistently associated with better outcomes than fully virtual education. While one might anticipate that the additional schooling support provided by hybrid education would relieve some of the parental burden, the effect may have been too small to measure or was balanced out by the negative effect of breaking up weekly routines (Conger \& Conger, 2002; Prime, Wade, \& Browne, 2020). Of course, relieving familial distress is not the only goal: hybrid education may improve education outcomes or child mental health, though systematic data on this topic remains limited and largely based on subject report (Bassok, Weisner, Markowitz, \& Hall, 2021, 2021).

\section{Limitations}

The present study has some significant advantages over most prior work: unusually large datasets and a reasonably clean manipulation in the form of a natural experiment (the pandemic). However, there are limitations. While the KidTalk data - both here and in Hartshorne et al. (2021) - suggest that schooling policy affected screen time, etc., via increased childcare burden on parents, none of the large national surveys solicited detailed information about childcare burden. Hartshorne et al. (2021) circumvented this issue in part by looking at school closure dates in the communities that survey respondents lived in. Unfortunately, publicly available records about when schools reopened and in what capacity are extremely limited (Lupton-Smith et al., 2021). Even where they exist, there is often variability within district (only some schools are open in-person), within school (only some grades are in-person), and even within classroom (only some children are attending in-person), vitiating the utility of population-level statistics. Thus, while data to date - and 
common sense - both suggest that the effect of schooling policy was via childcare burden, it would be ideal to have more data, and common sense is sometimes wrong.

Relatedly, while "fully in-person" is a straightforward category, what was meant by "fully virtual" or "hybrid" could vary considerably across schools. Fully virtual might involve full-time live teacher interaction, largely asynchronous interaction, or little-to-no interaction of any kind. Hybrid could mean a few hours a week in-person, or multiple days per week. The heterogeneity of these categories may partly explain why we often failed to detect differences between the two. Note that this is not an issue specific to the present study but again reflects the chaotic nature of the pandemic period and the limits of available records.

While we addressed a number of confounds, it remains the case that school reopening policies were not randomly distributed around the country or even within communities. There may be social or cultural confounds driving our observed effects. Note that this was not an issue for the pre/post analyses of Hartshorne et al. (2021), since school closures happened nearly everywhere simultaneously, and results could be observed within-family and within-community. The fact that the Hartshorne et al. (2021) results are consistent mitigates the concern somewhat, but not entirely. Hartshorne et al. (2021) investigated the effects of losing childcare, which may not be fully symmetrical with the situation studied here: regaining childcare. It will be possible to further address this issue in the Fall, when most schools are expected to be fully in-person again.

More generally, however, the pandemic period was unique in a number of ways. The best way to confirm that results are not specific to some unidentified aspect of the pandemic period is to have converging results from other natural and artificial experiments.

We should also note that some datasets lacked information about one or another confound, making it impossible to address all confounds in all datasets. Moreover, we had no dataset with both screen time and work-from-home information, making it impossible to test the effect of the latter on the former. This concern is somewhat mitigated - but not eliminated - by the fact that it is not clear that work-from-home status was reliably confounded with schooling policy.

\section{Conclusions}

These findings strongly argue against the cultural problems with cultural solutions hypothesis, at least with respect to screen time and parent mental health. Public policy has frequently treated screen time and parent mental health as things to address through education: training parents to control screen time, use good mental health practices, and create a peaceful family environment. By implication, parents who do not succeed in such things are doing it wrong out because they do not know better. However, it strains credulity to suppose that millions of parents suddenly forgot good parenting practices in early 2020, coincidentally at the exact same time that schools closed (Hartshorne et al., 2021), or that sending their children back to in-person education jogged their memory of these practices. There is no reason to suppose parents' beliefs and desires changed radically during the pandemic, but their capacity to act on those beliefs and desires certainly did. Moreover, parents whose circumstances changed more changed their behavior more. 
These findings also call into question the supposed causal relationship between, for instance, screen time and poor developmental outcomes. Data are equally consistent with both screen time and poor developmental outcomes being common effects of the same underlying problem: insufficient familial resources.

None of this is to say that parents have nothing to learn about parenting, or that they would not benefit from tips and tricks, mental health counselling, or free books. But these results should make us question whether such interventions will succeed if the parents do not have the bandwidth to act on them. 


\section{Supplementary Online Materials}

\section{${ }_{513} \quad$ KidTalk Demographics}

Table SI1

Race of survey respondents to the KidTalk Pandemic Parenting Survey, Wave 2.

\begin{tabular}{lll}
\hline Race & $\mathrm{n}$ & Percent of Respondents \\
\hline White/Caucasian & 123 & $75.93 \%$ \\
More than one race & 15 & $9.26 \%$ \\
Latinx or Hispanic & 11 & $6.79 \%$ \\
Asian & 6 & $3.7 \%$ \\
Other & 3 & $1.85 \%$ \\
African-American/Black & 2 & $1.23 \%$ \\
Native Hawaiian or Pacific Islander & 1 & $0.62 \%$ \\
Did not respond & 1 & $0.62 \%$ \\
\hline
\end{tabular}

Table SI2

Race of survey respondents to the KidTalk Pandemic Parenting Survey, Wave 3.

\begin{tabular}{lll}
\hline Race & $\mathrm{n}$ & Percent of Respondents \\
\hline White/Caucasian & 381 & $83.01 \%$ \\
More than one race & 29 & $6.32 \%$ \\
Asian & 25 & $5.45 \%$ \\
Latinx or Hispanic & 10 & $2.18 \%$ \\
Other & 9 & $1.96 \%$ \\
African-American/Black & 4 & $0.87 \%$ \\
Native American & 1 & $0.22 \%$ \\
\hline
\end{tabular}


Table SI3

Parental reports of worries about having enough food and money, themselves or a family member getting sick, and "everything else" from Wave 2 of the KidTalk Survey, on a 5-point scale from -2 to +2 .

\begin{tabular}{l|l|l|l}
\hline Outcome Measure & Fully In Person & Hybrid & Fully Virtual \\
\hline \multirow{3}{*}{ Food and Money } & $\mathrm{M}=-1.46$ & $\mathrm{M}=-1.26$ & $\mathrm{M}=-1.59$ \\
\cline { 2 - 4 } & $\mathrm{SD}=0.87$ & $\mathrm{SD}=1.1$ & $\mathrm{SD}=0.75$ \\
\cline { 2 - 4 } & $\mathrm{N}=37$ & $\mathrm{~N}=19$ & $\mathrm{~N}=104$ \\
\hline \multirow{3}{*}{ Illness } & $\mathrm{M}=-0.35$ & $\mathrm{M}=-0.21$ & $\mathrm{M}=0.04$ \\
\cline { 2 - 4 } & $\mathrm{SD}=0.98$ & $\mathrm{SD}=1.03$ & $\mathrm{SD}=1.01$ \\
\cline { 2 - 4 } & $\mathrm{N}=37$ & $\mathrm{~N}=19$ & $\mathrm{~N}=104$ \\
\hline \multirow{3}{*}{ Other } & $\mathrm{M}=0.27$ & $\mathrm{M}=0.47$ & $\mathrm{M}=0.56$ \\
\cline { 2 - 4 } & $\mathrm{SD}=1.15$ & $\mathrm{SD}=0.96$ & $\mathrm{SD}=1.11$ \\
\cline { 2 - 4 } & $\mathrm{N}=37$ & $\mathrm{~N}=19$ & $\mathrm{~N}=104$ \\
\hline
\end{tabular}

Table SI4

Parental reports of worry and happiness on a scale of 0 to 4 and relative stress compared to pre-pandemic baseline on a scale of 0 to 10 for the 459 parents who met inclusion criteria and completed Wave 3 of the KidTalk Survey.

\begin{tabular}{l|l|l|l}
\hline Outcome Measure & Fully In Person & Hybrid & Fully Virtual \\
\hline \multirow{4}{*}{ Stress } & $\mathrm{M}=7.02$ & $\mathrm{M}=7.15$ & $\mathrm{M}=7.25$ \\
\cline { 2 - 4 } & $\mathrm{SD}=1.84$ & $\mathrm{SD}=2.23$ & $\mathrm{SD}=1.81$ \\
\cline { 2 - 4 } & $\mathrm{N}=123$ & $\mathrm{~N}=93$ & $\mathrm{~N}=238$ \\
\hline \multirow{3}{*}{ Worry } & $\mathrm{M}=1.95$ & $\mathrm{M}=2.03$ & $\mathrm{M}=2.15$ \\
\cline { 2 - 4 } & $\mathrm{SD}=0.99$ & $\mathrm{SD}=0.93$ & $\mathrm{SD}=0.96$ \\
\cline { 2 - 4 } & $\mathrm{N}=123$ & $\mathrm{~N}=92$ & $\mathrm{~N}=237$ \\
\hline \multirow{3}{*}{ Happiness } & $\mathrm{M}=2.37$ & $\mathrm{M}=2.28$ & $\mathrm{M}=2.21$ \\
\cline { 2 - 4 } & $\mathrm{SD}=0.67$ & $\mathrm{SD}=0.7$ & $\mathrm{SD}=0.67$ \\
\cline { 2 - 4 } & $\mathrm{N}=122$ & $\mathrm{~N}=92$ & $\mathrm{~N}=234$ \\
\hline
\end{tabular}

\section{Detailed stress results for KidTalk}

Parents in KidTalk Wave 2 reported levels of worry about having enough food and money, themselves or a family member getting sick, and "everything else" (Table SI3). Worry levels were generally the lowest for the fully in-person group, with the exception of "food and money," where the fully virtual group edged them out. However, one-way ANOVAs did not reach significance for any of the three measures (food \& money: $F(2,159)=1.27$, $M S E=0.67, p=.284, \hat{\eta}_{G}^{2}=.016$; sickness: $F(2,159)=1.85, M S E=1.04, p=.160$, $\hat{\eta}_{G}^{2}=.023$; all else: $\left.F(2,157)=0.92, M S E=1.22, p=.399, \hat{\eta}_{G}^{2}=.012\right)$. Parents in KidTalk Wave 3 reported current levels of worry and happiness, as well as level of stress compared to a pre-pandemic baseline. While stress and worry were reduced and happiness was higher in fully in-person schooling contexts (Table SI4), one-way ANOVAs again did not reach significance on any of the measures with respect to schooling policy (stress: $F(2,451)=0.61$, $M S E=3.64, p=.545, \hat{\eta}_{G}^{2}=.003$, worry: $F(2,449)=1.90, M S E=0.92, p=.151$, $\hat{\eta}_{G}^{2}=.008$, happiness: $\left.F(2,445)=2.22, M S E=0.46, p=.109, \hat{\eta}_{G}^{2}=.010\right)$. 


\section{Child screen time}

Accounting for COVID Prevalence. For ABCD, we fit models of screen time with main effects of both schooling policy and pandemic prevalence, as well as their interaction. The ABCD data only collected the relevant variables during one of the three data-collection waves, so statistical power was limited and perhaps for this reason no effects were significant (number of contacts with COVID: $p \mathrm{~s}>=0.49$; self-assessed risk of getting COVID: $p \mathrm{~s}>=$ $0.081)$.

We submitted PHQ4 scores from Understanding America to a model with linear predictors of schooling policy and self-assessed risk of contracting COVID in the next 3 months. There was a significant main effect such that greater self-assessed risk predicted worse mental health $\left(F(1,12,831)=83.31, M S E=8.61, p<.001, \hat{\eta}_{G}^{2}=.006\right)$. However, the main effect of schooling policy remained significant $(F(2,12,831)=19.09, M S E=8.61$, $\left.p<.001, \hat{\eta}_{G}^{2}=.003\right)$ and the interaction was not significant $(F(2,12,831)=0.55, M S E=$ $\left.8.61, p=.579, \hat{\eta}_{G}^{2}=.000\right)$. We conducted similar analyses consider number of known individuals diagnosed with COVID. There was no effect of number of known individuals $\left(F(1,8,173)=0.45, M S E=8.22, p=.502, \hat{\eta}_{G}^{2}=.000\right)$ but the effect of schooling policy remained significant $\left(F(2,8,173)=19.51, M S E=8.22, p<.001, \hat{\eta}_{G}^{2}=.005\right)$.

\section{Accounting for employment}

We fit models of screen time with main effects of both schooling policy and income loss as well as their interaction. Loss of income was increased with increased screen time $\left(F(1,6022)=23.47, M S E=10.51, p<.001, \hat{\eta}_{G}^{2}=.004\right)$ for ABCD but not KidTalk Wave 2 $\left(F(1,156)=2.12, M S E=1.25, p=.148, \hat{\eta}_{G}^{2}=.013\right)$ or KidTalk Wave $3(F(1,436)=0.01$, $\left.M S E=5.17, p=.913, \hat{\eta}_{G}^{2}=.000\right)$. Critically, the overall effect of schooling policy remained in the same directions and significant for all three datasets (KidTalk Wave 2: $F(2,156)=12.84$, $M S E=1.25, p<.001, \hat{\eta}_{G}^{2}=.141$; KidTalk Wave3: $F(2,436)=7.54, M S E=5.17, p=.001$, $\hat{\eta}_{G}^{2}=.033$; ABCD: $\left.F(2,6022)=3.80, M S E=10.51, p=.022, \hat{\eta}_{G}^{2}=.001\right)$. Moreover, in no case was the interaction significant (KidTalk Wave 2: $F(2,156)=1.12, M S E=1.25$, $p=.329, \hat{\eta}_{G}^{2}=.014$; KidTalk Wave3: $F(2,436)=0.49, M S E=5.17, p=.612, \hat{\eta}_{G}^{2}=.002$; ABCD: $\left.F(2,6022)=1.54, M S E=10.51, p=.214, \hat{\eta}_{G}^{2}=.001\right)$. Note that because the Understanding America and Census datasets did not include screen time measures, these were not reanalyzed.

Accounting for working from Home. No datasets included both screen time and work-from-home information, so the effect of work-from-home rates on screen time could not be directly investigated.

\section{Parent Mental Health}

Accounting for COVID Prevalence. See main text

\section{Accounting for employment}

Understanding America and the Census both had data on parent mental health and employment. (Because the KidTalk mental health findings were not fully significant, we did not re-analyze them.) We submitted PHQ4 scores from the Understanding America data to 
a model with linear predictors of schooling policy and whether the respondent was in the labor market but unemployed (approximately half the respondents), and their interactions. Both main effects were significant (school policy: $F(2,4,122)=5.06, M S E=7.91, p=.006$, $\hat{\eta}_{G}^{2}=.002$; unemployed: $\left.F(1,4,122)=123.35, M S E=7.91, p<.001, \hat{\eta}_{G}^{2}=.029\right)$, but the interaction was not $\left(F(2,4,122)=2.00, M S E=7.91, p=.135, \hat{\eta}_{G}^{2}=.001\right)$. Critically, marginal effects tests revealed that even among those who were not unemployed, mental health was better when the child was in fully in-person schooling relative to fully virtual schooling $(\Delta M=-0.38,95 \%$ CI $[-0.65,-0.11], t(4,122)=-3.34, p=.002, \mathrm{~d}=0.13)$ or hybrid schooling $(\Delta M=-0.34,95 \%$ CI $[-0.65,-0.03], t(4,122)=-2.56, p=.028$, $\mathrm{d}=0.12)$. As with the full dataset, the difference between fully virtual and hybrid was not significant $(\Delta M=0.04,95 \%$ CI $[-0.25,0.33], t(4,122)=0.34, p=.940, \mathrm{~d}=0.015)$. Complementary results were obtained by reanalyzing the Census data. We submitted PHQ4 scores to a model with linear predictors of days of instruction and whether the respondent had lost employment due to the pandemic, along with their interaction. Again, there were main effects of schooling $\left(F(1,261,804)=1,171.23, M S E=12.70, p<.001, \hat{\eta}_{G}^{2}=.004\right)$ and unemployment $\left(F(1,261,804)=4,096.49, M S E=12.70, p<.001, \hat{\eta}_{G}^{2}=.015\right)$, but critically no interaction $\left(F(1,261,804)=1.31, M S E=12.70, p=.252, \hat{\eta}_{G}^{2}=.000\right)$. Importantly, investigation of marginal trends showed clear trends towards better mental health with increased days of instruction, whether the repondent had lost employment $(\mathrm{b}=-0.1337045$, $\mathrm{CI}=[-0.168865,-0.09854405])$ or not $(\mathrm{b}=-0.1549378, \mathrm{CI}=[-0.168865,-0.1458516])$.

Accounting for working from Home. See main text

\section{Additional Data Sets}

One additional data set was obtained and analyzed but not fully reported here. Specifically, we hoped to compare rates of streaming of child-oriented media in communities where schools were in-person, online, or hybrid. Unfortunately, the data we obtained (from Reelgood, a streaming search service) was aggregated at the state level, and most states had considerable variation from community to community. More problematically, there is no official data on schooling status - whether for specific communities or in aggregate - prior to late February 2021. Various private entities have attempted to estimate schooling status (e.g., Burbio, Covid-19 School Response Dashboard, Return to Learn), however these data sets are incomplete and disagree with one another. Given these facts, it is not surprising we were unable to obtain clear results from analyses. Nonetheless, readers may wish to consider this file drawer investigation when interpreting the reported results.

\section{Exploratory analyses}

We conducted three exploratory analyses, described here for completeness.

Child Mental Health. We investigated the effect of schooling status on child mental health and relationships. While the results were promising (generally, in-person schooling was associated with better mental health), our focus here is on parents, and there are already many other, better investigations of pandemic-era child mental health (e.g., Orgilés, Morales, Delvecchio, Mazzeschi, \& Espada, 2020). Thus, we did not pursue this question and do not report results here. 
Time spent on schoolwork. Second, adolescents attending virtual school reported how much time they engaged in online schooling. The relevance of this to our research questions is not clear - anecdotally, some parents report that more online schooling is helpful while others report it is an additional burden - and indeed it did not correlate significantly with our key outcome measures. Unfortunately, neither ABCD nor any other data set reported how much time was spent physically at school, for which our predictions are more straightforward.

Family dynamics. The ABCD dataset included measures of family dynamics. Adolescents differed in their rating of the quality of their relationship with the rest of the family, depending on schooling policy $\left(F(2,6,426)=4.66, M S E=0.60, p=.009, \hat{\eta}_{G}^{2}=.001\right)$. Pairwise Tukey contrasts revealed adolescents reported better family relationships when in fully in-person schooling compared to those in fully virtual schooling $(\Delta M=0.20,95 \% \mathrm{CI}$ $[0.05,0.35], t(6,426)=3.05, p=.006$, Cohen's $\mathrm{d}=0.25)$ and a trend towards significantly better relationships in comparison to those in hybrid schooling $(\Delta M=-0.19,95 \%$ CI $[-0.39,0.02], t(6,426)=-2.10, p=.089$, Cohen's $\mathrm{d}=0.23)$. The difference between hybrid and fully virtual schooling did not reach significance $(\Delta M=0.01,95 \%$ CI $[-0.13,0.16]$, $t(6,426)=0.18, p=.983$, Cohen's d $=0.014)$.

Parents reported two measures of family conflict: pandemic-related change in "family stress and discord" and also "family conflict." We combined these two measures into a single average, which did not show an effect of schooling status $(F(2,6,512)=1.93, M S E=1.19$, $\left.p=.146, \hat{\eta}_{G}^{2}=.001\right)$.

Thus, adolescents reported better relationships with their family members when in fully in-person schooling, but parents did not report different levels of familial conflict. Determining whether this represents differences in perspective, differences in the questions asked, or a statistical fluke will require further investigation. 
Adelantado-Renau, M., Moliner-Urdiales, D., Cavero-Redondo, I., Beltran-Valls, M. R., Martínez-Vizcaíno, V., \& Álvarez-Bueno, C. (2019). Association between screen media use and academic performance among children and adolescents: A systematic review and meta-analysis. JAMA Pediatrics, 173, 1058-1067. https://doi.org/10.1001/jamapediatri cs.2019.3176

Androutsos, O., Perperidi, M., Georgiou, C., \& Chouliaras, G. (2021). Lifestyle changes and determinants of children's and adolescents' body weight increase during the first COVID-19 lockdown in greece: The COV-EAT study. Nutrients, 13(3), 930.

Aust, F., \& Barth, M. (2020). papaja: Create APA manuscripts with $R$ Markdown. Retrieved from https://github.com/crsh/papaja

Barnett, W. S., \& Jung, K. (2021). Seven impacts of the pandemic on young children and their parents: Initial findings from NIEER's december 2020 preschool learning activities survey. National Institute for Early Education Research.

Bassok, D., Weisner, K., Markowitz, A. J., \& Hall, T. (2021). Teaching young children during COVID-19: Lessons from early educators in louisiana. EdPolicyWorks at the University of Virginia. https://files. elfsightcdn. com ....

Bond, E. C., Dibner, K., \& Schweingruber, H. (Eds.). (2020). Reopening K-12 Schools During the COVID-19 Pandemic. Washington, DC: The National Academies Press. https://doi.org/10.17226/25858

Bronikowska, M., Krzysztoszek, J., Łopatka, M., Ludwiczak, M., \& Pluta, B. (2021). Comparison of physical activity levels in youths before and during a pandemic lockdown. International Journal of Environmental Research and Public Health, $18(10), 5139$.

Carroll, N., Sadowski, A., Laila, A., Hruska, V., Nixon, M., Ma, D. W. L., \& Haines, J. (2020). The impact of covid-19 on health behavior, stress, financial and food security among middle to high income canadian families with young children. Nutrients, 12(8), 1-14. https://doi.org/10.3390/nu12082352

Conger, R. D., \& Conger, K. J. (2002). Resilience in Midwestern families: Selected findings from the first decade of a prospective, longitudinal study. Journal of Marriage and Family, 64(2), 361-373. https://doi.org/10.1111/j.1741-3737.2002.00361.x

COVID-19 school response dashboard. (2021). https://covidschooldashboard.com.

Ericsson, K. A. (2014). Why expert performance is special and cannot be extrapolated from studies of performance in the general population: A response to criticisms. Intelligence, 45, 81-103.

Faught, E. L., Ekwaru, J. P., Gleddie, D., Storey, K. E., Asbridge, M., \& Veugelers, P. J. (2017). The combined impact of diet, physical activity, sleep and screen time on academic achievement: A prospective study of elementary school students in Nova Scotia, Canada. International Journal of Behavioral Nutrition and Physical Activity, 14, 29. https://doi.org/10.1186/s12966-017-0476-0

Fields, J., Hunter-Childs, J., Tersine, A., Sisson, J., Parker, E., Velkoff, V., ... Shin, H. (2020). Design and operation of the 2020 household pulse survey. US Census Bureau, Forthcoming.

Gilbert, L. K., Strine, T. W., Szucs, L. E., Crawford, T. N., Parks, S. E., Barradas, D. T., ... Ko, J. Y. (2020). Racial and Ethnic Differences in Parental Attitudes and Concerns About School Reopening During the COVID-19 Pandemic - United States, July 2020. MMWR. Morbidity and Mortality Weekly Report, 69(49), 1848-1852. 
https://doi.org/10.15585/mmwr.mm6949a2

Gilkerson, J., Richards, J. A., \& Topping, K. (2017). Evaluation of a LENA-based online intervention for parents of young children. Journal of Early Intervention, 39(4), 281-298.

Glass, J., Simon, R. W., \& Andersson, M. A. (2016). Parenthood and happiness: Effects of work-family reconciliation policies in 22 oecd countries. American Journal of Sociology, 122(3), 886-929. https://doi.org/10.1086/688892

Grolemund, G., \& Wickham, H. (2011). Dates and times made easy with lubridate. Journal of Statistical Software, 40(3), 1-25. Retrieved from https://www.jstatsoft.org/v40/i03/

Harris, J. R. (2011). The nurture assumption: Why children turn out the way they do. Simon; Schuster.

Hartshorne, J. K., Huang, Y. T., Aulestia, P. M. L. P., Oppenheimer, K., Robbins, P. T., \& Molina, M. D. V. (2021). Screen time as an index of family distress. Current Research in Behavioral Sciences, 100023. https://doi.org/https://doi.org/10.1016/j.crbeha.2021. 100023

Johnson, A. D., \& Padilla, C. M. (2019). Childcare instability and maternal depressive symptoms: Exploring new avenues for supporting maternal mental health. Academic Pediatrics, 19, 18-26. https://doi.org/10.1016/j.acap.2018.05.006

Kahneman, D., \& Tversky, A. (2013). Choices, values, and frames. In Handbook of the fundamentals of financial decision making: Part $i$ (pp. 269-278). World Scientific.

Kapteyn, A., Angrisani, M., Bennett, D., Bruin, W. B. de, Darling, J., Gutsche, T., ... others. (2020). Tracking the effect of the COVID-19 pandemic on the lives of american households. In Survey research methods (Vol. 14, pp. 179-186).

Kroenke, K., Spitzer, R. L., Williams, J. B. W., \& Löwe, B. (2009). An Ultra-Brief Screening Scale for Anxiety and Depression: The PHQ-4. Psychosomatics, 50(6), 613-621. https://doi.org/10.1016/s0033-3182(09)70864-3

Kurtz, H. (2021). Teachers in Schools , Capitol Insurrection Lessons, Biden's Reopening Plans: Survey Results. Online. Retrieved from https://www.edweek.org/leadershi $\mathrm{p} /$ teachers-in-schools-capitol-insurrection-lessons-bidens-reopening-plans-surveyresults/2021/02

Lupton-Smith, C., Goicoechea, E. B., Collins, M., Lessler, J., Grabowski, M. K., \& Stuart, E. A. (2021). Consistency between household and county measures of k-12 onsite schooling during the COVID-19 pandemic. arXiv Preprint arXiv:2103.13296.

Madigan, S., McArthur, B. A., Anhorn, C., Eirich, R., \& Christakis, D. A. (2020). Associations between screen use and child language skills: A systematic review and meta-analysis. JAMA Pediatrics, 174(7), 665-675. https://doi.org/10.1001/jamapediatrics.2020.0327

Map: Where are schools required to be open? (2021). Education Week. Education Week; Education Week. Retrieved from https://www.edweek.org/leadership/map-where-areschools-closed /2020/07

Medrano, M., Cadenas-Sanchez, C., Oses, M., Arenaza, L., Amasene, M., \& Labayen, I. (2021). Changes in lifestyle behaviours during the COVID-19 confinement in spanish children: A longitudinal analysis from the MUGI project. Pediatric Obesity, 16(4), e12731.

Mikolajczak, M., \& Roskam, I. (2018). A theoretical and clinical framework for parental burnout: The balance between risks and resources (BR2). Frontiers in Psychology, 9, 886. 
Mundy, L. K., Canterford, L., Hoq, M., Olds, T., Moreno-Betancur, M., Sawyer, S., ... Patton, G. C. (2020). Electronic media use and academic performance in late childhood: A longitudinal study. Plos One, 15(9), e0237908.

Ng, K., Cooper, J., McHale, F., Clifford, J., \& Woods, C. (2020). Barriers and facilitators to changes in adolescent physical activity during COVID-19. BMJ Open Sport 83 Exercise Medicine, 6(1), e000919.

Obama, F. L. M. (2012). Let's move! Raising a healthier generation of kids. Childhood Obesity, $8(1), 1$.

Olive, L., Sciberras, E., Berkowitz, T. S., Hoare, E., Rohan.Telford, Mikocka-Walus, A., ... al., et. (2020). Child and parent physical activity, sleep and screen time during COVID-19 compared to pre-pandemic nationally representative data and associations with mental health. PsyArXiv. https://doi.org/10.31234/osf.io/anqct

Orben, A., \& Przybylski, A. K. (2019). The association between adolescent well-being and digital technology use. Nature Human Behaviour, 3(2), 173-182.

Organization, W. H.others. (2019). Guidelines on physical activity, sedentary behaviour and sleep for children under 5 years of age. World Health Organization. Retrieved from https://www.who.int/publications/i/item/9789241550536

Orgilés, M., Morales, A., Delvecchio, E., Mazzeschi, C., \& Espada, J. P. (2020). Immediate psychological effects of the COVID-19 quarantine in youth from italy and spain. Frontiers in Psychology, 11, 2986.

Oswald, A. R. A. K., Tassia K. AND Rumbold, \& Moore, V. M. (2020). Psychological impacts of "screen time" and "green time" for children and adolescents: A systematic scoping review. PLOS ONE, 15(9), 1-52. https://doi.org/10.1371/journal.pone.0237725

Parkes, A., Sweeting, H., \& Wight, D. (2015). Parenting stress and parent support among mothers with high and low education. Journal of Family Psychology, 29(6), 907. https: //doi.org/10.1037/fam0000129

Paterson, D. C., Ramage, K., Moore, S. A., Riazi, N., Tremblay, M. S., \& Faulkner, G. (2021). Exploring the impact of COVID-19 on the movement behaviors of children and youth: A scoping review of evidence after the first year. Journal of Sport and Health Science.

Pinker, S. (2003). The blank slate: The modern denial of human nature. Penguin.

Prime, H., Wade, M., \& Browne, D. T. (2020). Risk and resilience in family well-being during the COVID-19 pandemic. American Psychologist, 75(5), 631-643. https://doi.or $\mathrm{g} / 10.1037 / \mathrm{amp} 0000660$

Przybylski, A. K., \& Weinstein, N. (2017). A large-scale test of the goldilocks hypothesis: Quantifying the relations between digital-screen use and the mental well-being of adolescents. Psychological Science, 28(2), 204-215.

Puma, M., Bell, S., Cook, R., Heid, C., Shapiro, G., Broene, P., .. others. (2010). Head start impact study. Final report. Administration for Children $\& 5$ Families.

R Core Team. (2020). R: A language and environment for statistical computing. Vienna, Austria: R Foundation for Statistical Computing. Retrieved from https://www.Rproject.org/

Ransing, R., Ramalho, R., Orsolini, L., Adiukwu, F., Gonzalez-Diaz, J. M., Larnaout, A., ... Kilic, O. (2020). Can COVID-19 related mental health issues be measured? Brain, Behavior, and Immunity, 88(August), 32-34. 
Richtel, M. (2021). Children's screen time has soared in the pandemic, alarming parents and researchers. New York Times. Retrieved from https://www.nytimes.com/2021/01/ 16/health/covid-kids-tech-use.html

Robinson, G. E. (2004). Beyond nature and nurture. Science, 304(5669), 397-399.

Rugg, A. (2019). Working out their future: The NFL's play 60 campaign and the production of adolescent fans and players. Journal of Sport and Social Issues, 43(1), 69-88.

Sciberras, E., Patel, P., Stokes, M. A., Coghill, D., Middeldorp, C. M., Bellgrove, M. A., ... others. (2020). Physical health, media use, and mental health in children and adolescents with ADHD during the COVID-19 pandemic in australia. Journal of Attention Disorders, 1087054720978549 .

Smith, C. E. (2015). Examining the effectiveness of the babytalk home visiting service on parent talk to children and child language development: A randomised controlled trial. University of Surrey (United Kingdom).

Stienwandt, S., Cameron, E. E., Soderstrom, M., Casar, M. J., Le, C., \& Roos, L. E. (2020). Keeping kids busy: Family factors associated with hands-on play and screen time during the COVID-19 pandemic. PsyArXiv. https://doi.org/10.31234/osf.io/prtyf

Stiglic, N., \& Viner, R. M. (2019). Effects of screentime on the health and well-being of children and adolescents: A systematic review of reviews. BMJ Open, 9(1). https: //doi.org/10.1136/bmjopen-2018-023191

Suskind, D. L., Leffel, K. R., Graf, E., Hernandez, M. W., Gunderson, E. A., Sapolich, S. G., ... Levine, S. C. (2016). A parent-directed language intervention for children of low socioeconomic status: A randomized controlled pilot study. Journal of Child Language, $43(2), 366-406$.

Takaku, R., \& Yokoyama, I. (2020). What school closure left in its wake: Contrasting evidence between parents and children from the first COVID-19 outbreak. Available at SSRN 3693484 .

Talbot, M. (2015). The talking cure. The New Yorker, 90, 43.

Ten Velde, G., Lubrecht, J., Arayess, L., Loo, C. van, Hesselink, M., Reijnders, D., \& Vreugdenhil, A. (2021). Physical activity behaviour and screen time in dutch children during the COVID-19 pandemic: Pre-, during-and post-school closures. Pediatric Obesity, e12779.

Trinh, L., Wong, B., \& Faulkner, G. E. (2015). The independent and interactive associations of screen time and physical activity on mental health, school connectedness and academic achievement among a population-based sample of youth. Journal of the Canadian Academy of Child and Adolescent Psychiatry, 24, 17-24. Retrieved from https://www.nc bi.nlm.nih.gov/pmc/articles/PMC4357330/

Wickham, H. (2016). ggplot2: Elegant graphics for data analysis. Springer-Verlag New York. Retrieved from https://ggplot2.tidyverse.org

Wickham, H. (2019). Stringr: Simple, consistent wrappers for common string operations. Retrieved from https://CRAN.R-project.org/package=stringr

Wickham, H., Averick, M., Bryan, J., Chang, W., McGowan, L. D., François, R., ... Yutani, H. (2019). Welcome to the tidyverse. Journal of Open Source Software, 4(43), 1686. https://doi.org/10.21105/joss.01686

Wickham, H., François, R., Henry, L., \& Müller, K. (2021). Dplyr: A grammar of data manipulation. Retrieved from https://CRAN.R-project.org/package=dplyr 
814 Xie, Y. (2015). Dynamic documents with $R$ and knitr (2nd ed.). Boca Raton, Florida: 